\title{
A Novel, Domino Synthesis of Tricyclic Benzimidazole Derivatives Using Continuous Flow
}

\author{
Balázs Szabó1,2, Kiara Szakter¹, Angelika Thurner ${ }^{1}$, Ferenc Faigl ${ }^{1 *}$, János Éles², István Greiner² \\ 1 Department of Organic Chemistry and Technology, Budapest University of Technology and Economics, \\ H-1521 Budapest, P.O. Box 91, Hungary \\ 2 Chemical Works of Gedeon Richter Plc., H-1103 Budapest, Gyömrői út 19-21., Hungary \\ * Corresponding author, e-mail: ffaigl@mail.com
}

Received: 26 April 2019, Accepted: 19 July 2019, Published online: 17 October 2019

\begin{abstract}
A novel method for synthesis of tricyclic benzimidazole derivatives by using continuous flow reactor is reported. Disadvantages of the well-known batch methods have been avoided utilizing the flow chemistry technology. Beside the one pot reductive cyclization using $\mathrm{H}$-Cube $\mathrm{Pro}^{\circledR}$, the dehydration step was also optimized producing the desired lactam compounds. Then the acylation was optimized under microwave conditions and that reaction was also integrated into the flow system using an Asia heater module. This acylation dramatically reduced the reaction time under continuous-flow conditions, with a residence time of $30 \mathrm{~min}$.
\end{abstract}

Keywords

benzimidazole, lactam, heterocycles, continuous flow, reductive cyclization, one-pot

\section{Introduction}

Nitrogen containing bi- and tricyclic heterocyclic compounds bearing benzimidazole and pyrrolobenz-imidazole moieties are in the focus of the drug discovery interest, because of their comprehensive pharmacological applications. Without the necessity of completeness, the main indications are antitumor [1, 2], anti-inflammatory [2, 3], analgesic [4] and antibacterial [4-6] activities.

In order to highlight the need for a new synthetic procedure, we review the major procedures reported in literature taking 2,3-dihydro-1H-pyrrolo[1,2-a]benz-imidazole-1-one (1) as model compound. By examining literary examples, the main procedures can be divided into three groups (Fig. 1). The synthesis of $\mathbf{1}$ is achievable with the reaction of aryl diamine and the appropriate anhydride (Fig. 1, Path A). As we can see in Meegalla's work, this process is usually accomplished in two steps. First step is the acylation at $100{ }^{\circ} \mathrm{C}$ and then the water elimination is carried out on a higher $\left(\sim 180{ }^{\circ} \mathrm{C}\right)$ temperature reaching a relatively low overall yield (38\%) [7]. Another procedure is a solid-state condensation catalyzed by Lewis acid (zinc(II)acetate) using extremely high temperatures (from 220 to $300{ }^{\circ} \mathrm{C}$ ) [8]. Intramolecular cyclization of suitably substituted aromatic diamines (3a) is also described (Fig. 1, Path B). The ring closure can be carried out via

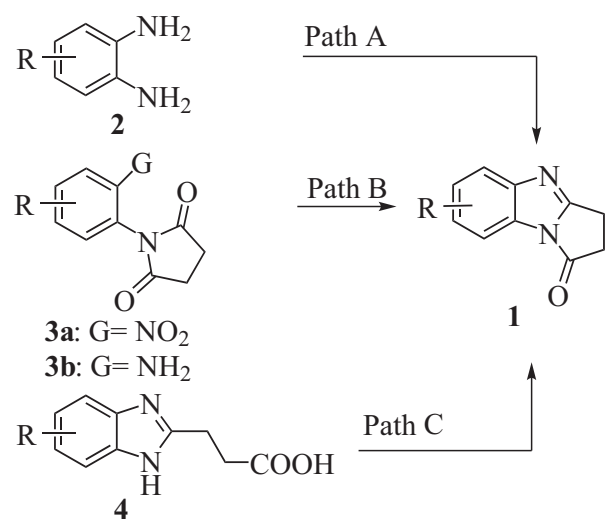

Fig. 1 The potential synthesis methods to 2,3-dihydro- $1 H$ pyrrolo[1,2-a]benzimidazole-1-one (1)

an intramolecular aza-Wittig reaction using phosphorus, arsenic, boronic or antimony phosphorane reagents [9-11]. Starting from benzimidazole-2-propanoic acid (4, Path C) the desired product (1) can be obtained with a dehydration step which feasibly with pyrolysis reaction [9] or with using acetic anhydride or thionyl chloride [12]. There is only a few example known in the literature, when the synthesis of 1 was implemented through nitro group reduction starting from $\mathbf{3 b}$ (Fig. 1, Path B). In each case, the reaction is carried out in two steps. In the first step the reduction of nitro group using $\mathrm{H}_{2}$ with $\mathrm{Pd} / \mathrm{C}$ catalyst or $\mathrm{Fe}$ in $\mathrm{AcOH}$ 
at $60{ }^{\circ} \mathrm{C}$ [13], or $\mathrm{SnCl}_{2} \cdot 2 \mathrm{H}_{2} \mathrm{O}$ at $85{ }^{\circ} \mathrm{C}$ for $12 \mathrm{~h}$ [14]. In the second step the ring closure is performed with $10 \% \mathrm{HCl}$ or $6 \mathrm{M} \mathrm{H}_{2} \mathrm{SO}_{4}$ [13], or with refluxing in DMF for $72 \mathrm{~h}$ to reach a low, $18 \%$ yield [14].

As can be seen from the examples listed above, these are typical of these processes to suffer from minor drawbacks such as use of corrosive and toxic catalysts, high temperatures, low yields and comparatively long reaction times. In our case, we decided to develop a two-step method for the synthesis of $1 H$-pyrrolo[1,2-a]benzimidazol-1-one derivatives. To the best of our knowledge no method has been reported in literature involving one-pot intramolecular reductive cyclization starting from suitably substituted $o$-nitroaniline. The use of flow technique as an enabling technology can mitigate these classical disadvantages, especially reduce the reaction time and exclude toxic reagents. Accordingly, our recent work has revealed that the one-pot reductive cyclization of $o$-nitroacetanilide derivatives can be carried out with almost quantitative yield and excellent tolerance towards different sensitive functionalities compared to the batch processes [15].

\section{Results and discussion}

We divided the experimental work into two constituent phases to separate key steps from the others, providing a modular approach. We began our experimentation with the optimization of reductive ring closure. Continuous flow hydrogenation reactions were performed on an H-Cube Pro ${ }^{\circledR}$ flow system, utilizing water electrolysis to generate hydrogen (by Thales Nano).

During the experiments we followed the optimal parameters defined in our previous study (solvent: acetic acid, 20 bar, $150{ }^{\circ} \mathrm{C}, 30 \mathrm{~mm} \mathrm{5 \%} \mathrm{Pt} / \mathrm{C}$, Sulfided catalyst cartridge),[15] and only the effect of residence time was investigated. Here we have to mention, that when we used other type of solvents such as ethanol (EtOH), toluene, ethyl acetate (EtOAc) or dichloromethane (DCM) blockage could be observed. The degree of conversion and product selectivity were readily established by monitoring the composition of the reaction mixture after the solvent evaporation by LC-MS analysis. As starting materials, we investigated open chain and cyclic $o$-nitroacylanilide derivatives $(\mathbf{5}, \mathbf{6}, \mathbf{1 1}, \mathbf{1 2})$ synthesized by conventional batch process. Based on the results we concluded, that the residence time has no effect on product selectivity and 2-(1H-benzo[d]imidazol-2-yl)alkanoic acids $(7,8)$ can be produced with good selectivity (94\%, Table 1). Due to the acidic media and the applied high temperature, dehydration step becomes a beneficiary causing a minimal amount of intramolecular lactam formation $(2 \%, 9,10)$ and the side chain length (in 6 vs 5) doesn't influence the rate of ring closure (Table 1).

Next, we examined the above reaction with $o$-nitro cyclic imides $(\mathbf{1 1}, \mathbf{1 2}$ in Fig. 3). In contrast with the previous findings, the residence time has a significant role in product selectivity. Increasing the flow rate $(0.3-$ $1.0 \mathrm{mLmin}^{-1}$ ) enrichment of hydroxy intermedier can be observed (Table 2, entry 8, $1.0 \mathrm{mLmin}^{-1}, 19 \%$ 13). Best selectivity towards the desired product ( $94 \% 9$, entry 5) is achievable with $0.3 \mathrm{mLmin}^{-1}$ flow rate. Here we have to mention, that the H-Cube Pro ${ }^{\circledR}$ flow system isn't stabile under this flow rate. To increase the residence time we used $70 \mathrm{~mm}$ catalyst cartridge (Table 2, entry 9). Surprisingly, significant ring opening takes place producing 7 (31\%). Based on this experience we concluded that there is equilibrium between the lactam (9) and the open chain (7) forms. Starting from compound 12, a small amount of ring opening product was observed (entry 10, $11 \% \mathbf{8}$ ).

After the optimization of one pot reduction and ring closure, we planned to reach the formation of $\mathbf{9}$ from $\mathbf{5}$ with a subsequent dehydration step. According to our flow system the crude product (contains $94 \% 7$ ) pumped from a liquid-gas separator into an Asia heater loop reactor module and at the end we used a back pressure regulator (BPR). As constant parameters we used $0.5 \mathrm{mLmin}^{-1}$ flow rate, and the above described parameters of reduction method (General procedure A).

The residence time of dehydration step was modified with the volume of the loop reactor ( 4 or $16 \mathrm{~mL}$ ). During the experiments we applied a back pressure regulator

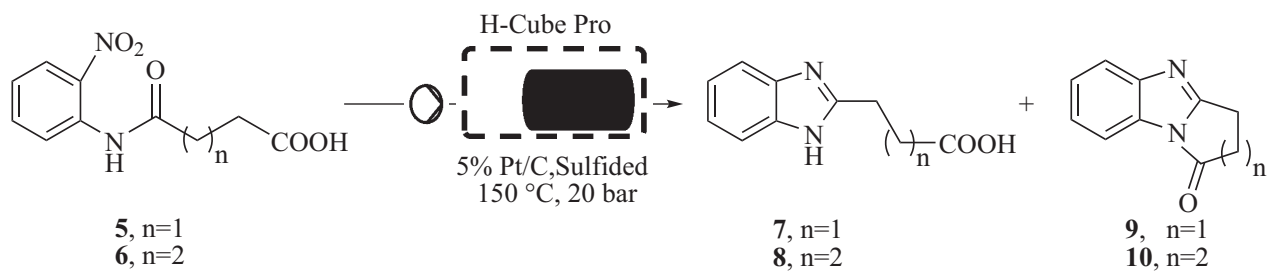

Fig. 2 Synthesis of 7, 9 and $\mathbf{8}, \mathbf{1 0}$ mixtures from $\mathbf{5}$ and $\mathbf{6}$, respectively 
Table 1 Optimization of one pot reduction and ring closure reaction sequence starting from $\mathbf{5}$ or $\mathbf{6}$. (General procedure A)

\begin{tabular}{lcccc}
\hline Entry & $\begin{array}{c}\text { Starting } \\
\text { material }\end{array}$ & $\begin{array}{c}\mathrm{V} \\
{\left[\mathrm{mLmin}^{-1}\right]}\end{array}$ & $\begin{array}{c}\mathbf{7 , 8} \\
{[\%]}\end{array}$ & $\begin{array}{c}\mathbf{9 , 1 0} \\
{[\%]}\end{array}$ \\
\hline 1 & $\mathbf{5}$ & 0.30 & 94 & 2 \\
2 & $\mathbf{5}$ & 0.75 & 94 & 3 \\
3 & $\mathbf{5}$ & 1.00 & 95 & 2 \\
4 & $\mathbf{6}$ & 0.50 & 93 & 2 \\
\hline
\end{tabular}

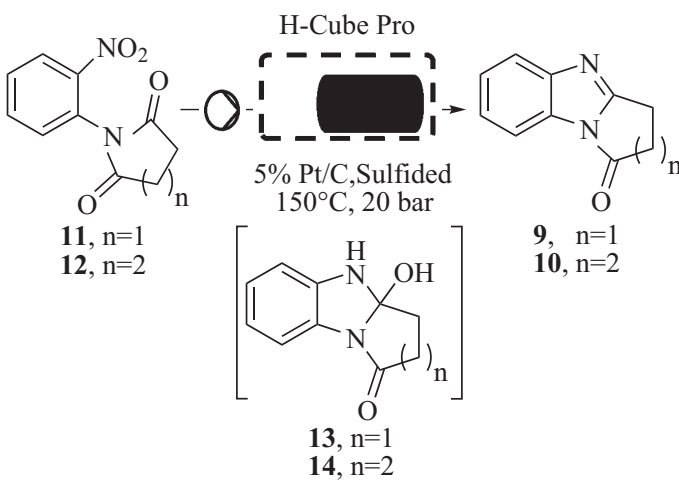

Fig. 3 Reductive ring closure of $\mathbf{1 1}$ and $\mathbf{1 2}$ in $\mathrm{H}-\mathrm{Cube} \mathrm{Pro}^{\circledR}$

of 250 psi, except in the case of the experiment made at $250{ }^{\circ} \mathrm{C}$ (Fig. 4, Table 3, entry 16, 350 psi). On the basis of these results one can conclude that on higher temperature the conversion of lactam formation increases. Furthermore, at the same temperature there are no considerable differences in the product selectivity depending on residence time. At $150{ }^{\circ} \mathrm{C}$ the dehydration rate is negligible (2-4\%, entries 11 and 12$)$, but at $250{ }^{\circ} \mathrm{C}$ selective formation of product 9 is reachable (64-60\%, entries 15-16).

Next, we aimed to integrate the acylation step to the reductive ring closure. Optimum conditions of the acylation were determined under batch conditions using microwave irradiation (Fig. 5). Microwave assisted optimization has been widely demonstrated as a synthetically useful tool in continuous flow chemistry research [16-18]. Microwave chemistry is suitable for reaction screening in a very short period of time and also appears perfectly suited to mimic both the rapid heating and the high temperatures attainable in a continuous flow chemistry experiment.
Table 2 Optimization of one pot reduction and ring closure reaction sequence starting from $\mathbf{1 1}$ or $\mathbf{1 2}$ (General procedure A).

\begin{tabular}{ccccc}
\hline Entry & $\begin{array}{c}\text { Starting } \\
\text { material }\end{array}$ & $\begin{array}{c}\mathrm{V} \\
{\left[\mathrm{mLmin}^{-1}\right]}\end{array}$ & $\begin{array}{c}\mathbf{1 3}, \mathbf{1 4} \\
{[\%]}\end{array}$ & $\begin{array}{c}\mathbf{9}, \mathbf{1 0} \\
{[\%]}\end{array}$ \\
\hline 5 & $\mathbf{1 1}$ & 0.30 & 1 & 94 \\
6 & $\mathbf{1 1}$ & 0.50 & 4 & 91 \\
7 & $\mathbf{1 1}$ & 0.75 & 12 & 82 \\
8 & $\mathbf{1 1}$ & 1.00 & 19 & 74 \\
$9 *$ & $\mathbf{1 1}$ & 0.50 & 0 & 56 \\
10 & $\mathbf{1 2}$ & 0.50 & 2 & 86 \\
\hline
\end{tabular}

*70 mm 5\% Pt/C Sulfided catalyst cartridge was used.

Table 3 results of cyclization reaction after reductive benzimidazole formation in flow system (General procedure B)

\begin{tabular}{lccccc}
\hline Entry & $\begin{array}{c}\text { Asia heater } \\
\text { volume }[\mathrm{mL}]\end{array}$ & $\begin{array}{c}\mathrm{T}_{1} \\
{\left[{ }^{\circ} \mathrm{C}\right]}\end{array}$ & $\begin{array}{c}\mathrm{t}_{1} \\
{[\mathrm{~min}]}\end{array}$ & $\begin{array}{c}7 \\
{[\%]}\end{array}$ & $\begin{array}{c}9 \\
{[\%]}\end{array}$ \\
\hline 11 & 4 & 150 & 8 & 84 & 2 \\
12 & 16 & 150 & 32 & 93 & 4 \\
13 & 4 & 200 & 8 & 40 & 56 \\
14 & 16 & 200 & 32 & 46 & 40 \\
15 & 4 & 250 & 8 & 20 & 64 \\
16 & 16 & 250 & 32 & 30 & 60 \\
\hline
\end{tabular}

Condensation of $o$-nitroaniline (15) with an excess of succinic anhydride (16, 3 eq.) was carried out by irradiating them in CEM-Explorer microwave oven for $30 \mathrm{~min}$ at $200^{\circ} \mathrm{C}$ at a power level of $220 \mathrm{~W}$ (Fig. 5). In the selection of the solvent, it was important to have an adequate solubility for each components and stability under the conditions of acylation and reductive ring closure steps. Taking into account the previous considerations, we used toluene as a fitting alternative. Initially, we used acetic acid as catalyst and with varying its ratio we screened the effect on the conversion and the selectivity of the reaction. The degree of conversion and product selectivity were readily established by monitoring the composition of the reaction mixture after the solvent evaporation by liquid chromatography-mass spectrometry (LC-MS) analysis (Fig. 6). The results showed that increasing the amount of acetic acid the main product (5) undergoes dehydration producing

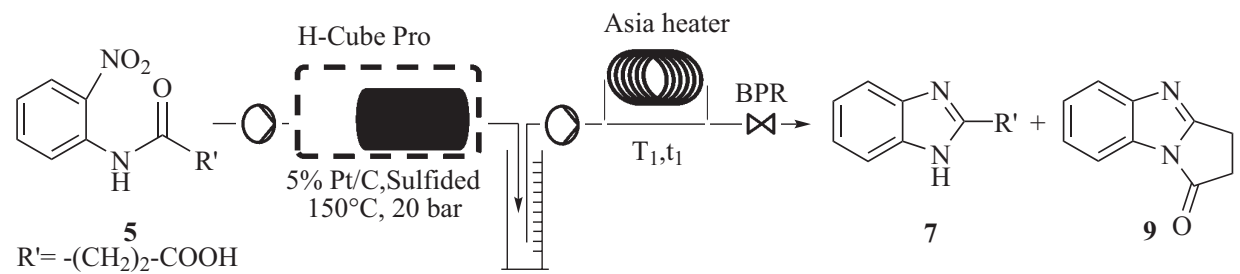

Fig. 4 Implementation of cyclization after reductive benzimidazole formation in flow system. (General procedure B) 


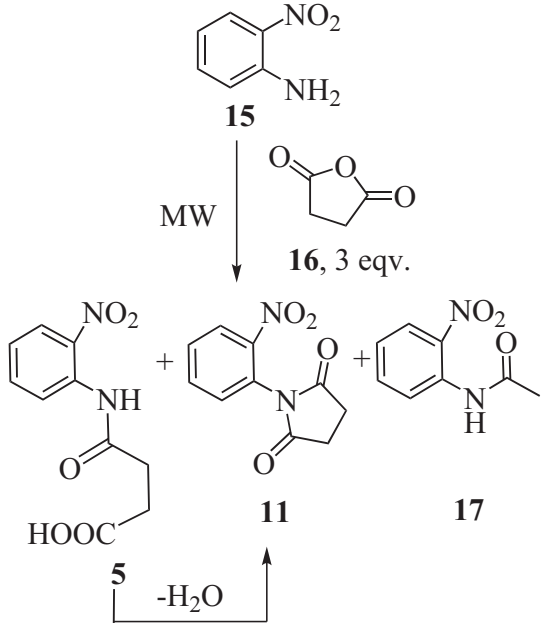

Fig. 5 o-Nitroaniline acylation with succinic anhydride using microwave irradiation (General procedure C)

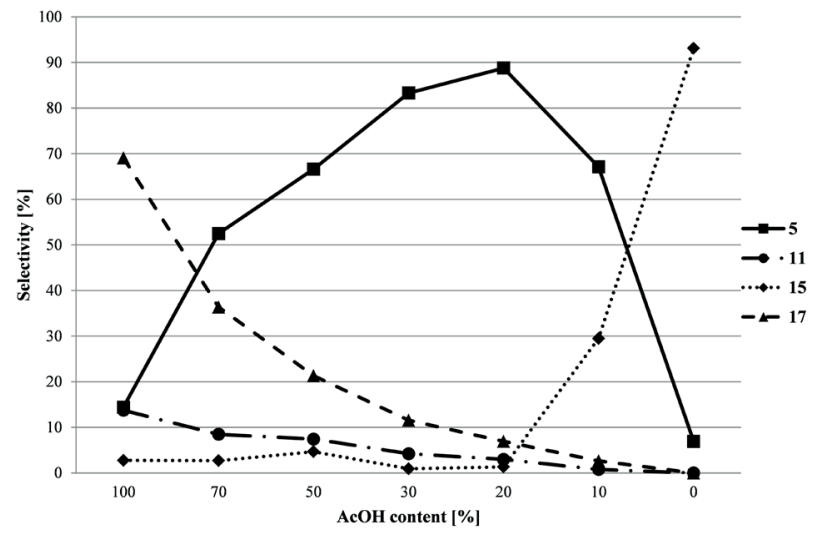

Fig. 6 The effect of the acetic acid content on the conversion of $\mathbf{1 5}$ into $\mathbf{5}, \mathbf{1 1}$ or $\mathbf{1 7}$ in toluene solution

compound 11. In addition, mixed anhydride of succinic acid and acetic acid formed which generated $o$-nitroacetanilide (17).

The rate of this side reaction increases with acetic acid content and reaches a maximum amount (69\%) using acetic acid as only solvent.

The analysis revealed that, under these conditions, maximum selectivity of 5 was achieved using 20 vol\% acetic acid in toluene solvent mixture with an almost full conversion $(1,3 \% \mathbf{1 5})$ but the conversion decreased dramatically when the acetic acid content was minimized (0\% AcOH, $93 \%$ 15).

In order to avoid the above mentioned mixed anhydride formation next we tried to use stronger acids in less amount. First, 2 equivalents of methanesulfonic acid was added, but white precipitate formation was observed which does not allow the integration into flow system. Then we used the commercially available sulfonic acid surface-modified
Amberlyst XN-1010 ion exchange resin. During these experiments we used 3 equivalents of succinic anhydride, 50 weight percent of catalyst, toluene as the only solvent and 30 minutes reaction time. We examined the effect of temperature on the conversion and selectivity. After the filtration of the resin, we monitored the composition of the reaction mixture by GC-MS analysis (Fig. 7). Surprisingly an almost full selectivity towards the succinimide type product $\left(96 \%\right.$ 11) was achieved at $200{ }^{\circ} \mathrm{C}$. As the temperature decreases the selectivity declines, and the conversion greatly decreases under $150{ }^{\circ} \mathrm{C}$. Unfortunately, we discovered white needle crystals in the resulted solvents of experiments measured above $150{ }^{\circ} \mathrm{C}$.

Based on previous experiences, we selected finally the acetic acid catalyzed system to integration into flow. According to our flow system, the solution of $\mathbf{1 5}$ and $\mathbf{1 6}$ in $20 \% \mathrm{AcOH}-80 \%$ toluene solvent mixture was pumped into an Asia heater loop reactor module which was directly attached to the H-Cube Pro ${ }^{\circledR}$ (Fig. 9 and Table 4, entries 17-20). Based on LC-MS results, under these conditions large amount of by-product was formed during the reductive ring closure. Furthermore, it can be said that longer residence time (Table 4, entry 18, $32 \mathrm{~min}, 35 \% 9$ ), and greater anhydride excess (Table 4, entry 20, 6 eq. 16, $47 \%$ 9), resulted in the formation of more lactam type product (9). We assumed, that the main reason of side reactions is the residual 2-hydroxy compound (18, Fig. 8) due to low acetic acid content, [13] which can undergo intermolecular coupling reactions.

In order to avoid accumulation of $\mathbf{1 8}$, in the next experiments we enhanced the acidity by addition acetic acid after the Asia heater within a T-mixer (Table 4, entry 21-26). The optimal parameters to produce the largest amount of $\mathbf{7}$ are 3 equivalents 16, $30 \mathrm{~min}$ reaction time for acylation and $80 \%$ acid content for reductive ring closure reaction (entry $23,72 \% 7$ ).

\section{Conclusion}

In conclusion, this work covers alternative synthetic methods to produce 2-(1H-benzo[d]imidazole-2-yl)alkanoic acids $(7,8)$ and 2,3-dihydro-1 $H$-pyrrolo[1,2-a]benzimidazole-1-one (9) or 3,4-dihydro-pyrido[1,2-a]benzimidazol-1(2H)-one (10) using continuous flow chemistry. Starting from $o$-nitro acylanilide derivatives $(\mathbf{5}, \mathbf{6}, \mathbf{1 1}, \mathbf{1 2})$, we have achieved good selectivities towards the desired products $(95 \% \mathbf{7}, 93 \% \mathbf{8}, 94 \% \mathbf{9}, 86 \% \mathbf{1 0})$. Applying a subsequent dehydration step, the lactam ring closed product is obtainable with good selectivity $(64 \%, 9)$. Short reaction 


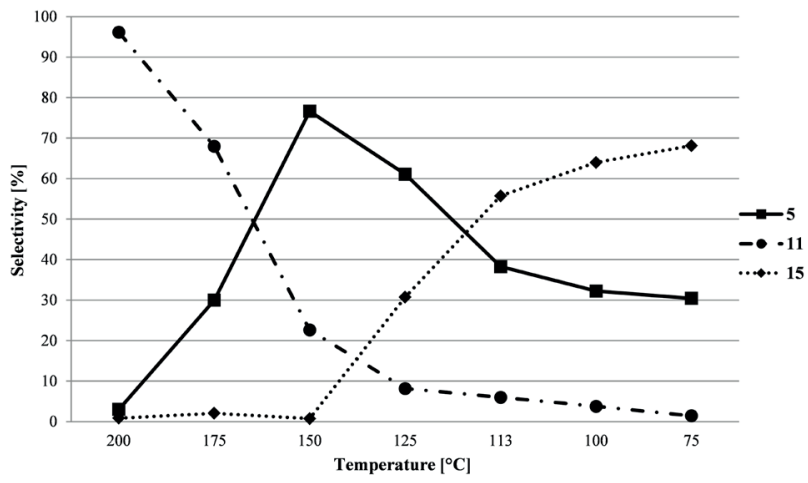

Fig. 7 Examination of the effect of the temperature on the acylation reaction using Amberlyst-XN-1010 as catalyst<smiles>O=C(O)CCC1(O)Nc2ccccc2N1</smiles>

18

Fig. 8 Structure of compound $\mathbf{1 8}$

times, and ease of continuous operation means this methodology offers a complementary alternative to existing literature procedures. We have demonstrated that with carefully selected solvent ratios and acylating agent excess, a good selectivity towards the desired $2-(1 H$-benzo[d]imidazol-2-propionic acid, or 2,3-dihydro-1H-pyrrolo[1,2-a] benzimidazole-1-one (7) is feasible connecting the acylation step into the reductive cyclisation step (72\% 7). In the cases of starting materials $\mathbf{5}$ and $\mathbf{6}$ the consecutive reaction steps, namely nitro group reduction, intramolecular ring closure, dehydration step and a second intramolecular ring closure were successfully connected in our flow system, providing a novel method for efficient preparation of the target compounds using domino reactions.

\section{Experimental \\ 4.1 General methods \\ 4.1.1 Chemicals}

All solvents, reagents and starting material 6 were purchased from commercial vendors and were used without further purification.

\subsubsection{Analytics}

${ }^{1} \mathrm{H}$ and ${ }^{13} \mathrm{C}$ NMR spectra were recorded on Bruker Avance III HD $400 \mathrm{MHz}$, Chemical shifts $(\delta)$ are given in parts per million (ppm) from an internal standard of tetramethylsilane $\left({ }^{1} \mathrm{H}\right.$ : $\left.0.00 \mathrm{ppm},{ }^{13} \mathrm{C}: 0.0 \mathrm{ppm}\right)$ or DMSO-d6 $\left({ }^{13} \mathrm{C}\right.$ : $39.4 \mathrm{ppm})$. All coupling constants $(\mathrm{J})$ are reported in Hertz $(\mathrm{Hz})$. The analysis of the reaction products were performed on an HPLC-MS. Experiments were carried out on an Agilent 1200 liquid chromatography system coupled with an 6410 QQQ-MS (Agilent Technologies, Palo

Table 4 results of the integration of acylation reaction into the flow system. (General procedure D)

\begin{tabular}{|c|c|c|c|c|c|c|c|}
\hline Entry & Anhydride eq. & $\begin{array}{c}\mathrm{V}_{1} \\
{\left[\mathrm{mLmin}^{-1}\right]}\end{array}$ & $\begin{array}{c}\text { Asia heater } \\
\text { volume }[\mathrm{mL}]\end{array}$ & $\begin{array}{c}\mathrm{T}_{1} \\
{\left[{ }^{\circ} \mathrm{C}\right]}\end{array}$ & $\begin{array}{c}\mathrm{V}_{2} \\
{\left[\mathrm{mLmin}^{-1}\right]}\end{array}$ & $\begin{array}{c}7 \\
{[\%]}\end{array}$ & $\begin{array}{c}9 \\
{[\%]}\end{array}$ \\
\hline 17 & 3 & 0.50 & 4 & 200 & - & 36 & 17 \\
\hline 18 & 3 & 0.50 & 16 & 200 & - & 31 & 35 \\
\hline 19 & 1.2 & 0.50 & 16 & 200 & - & 49 & 2 \\
\hline 20 & 6 & 0.50 & 16 & 200 & - & 16 & 47 \\
\hline 21 & 1.2 & 0.12 & 4 & 200 & 0.38 & 55 & 1 \\
\hline 22 & 1,2 & 0.12 & 4 & 200 & 0.88 & 56 & 1 \\
\hline 23 & 3 & 0.12 & 4 & 200 & 0.38 & 72 & 7 \\
\hline 24 & 3 & 0.12 & 4 & 200 & 0.88 & 60 & 5 \\
\hline 25 & 3 & 0.12 & 16 & 200 & 0.38 & 49 & 17 \\
\hline 26 & 3 & 0.12 & 16 & 200 & 0.88 & 59 & 22 \\
\hline
\end{tabular}

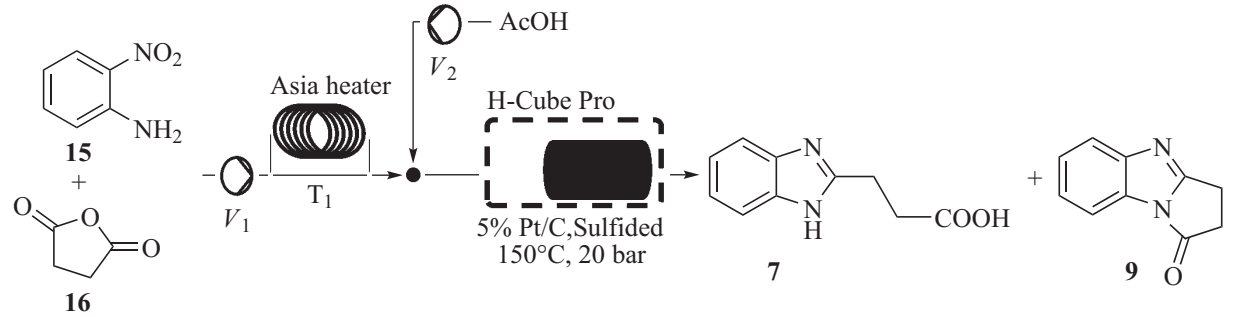

Fig. 9 The integration of acylation reaction into the flow system. (General procedure D) 
Alto, CA, USA). Analysis was at $40^{\circ} \mathrm{C}$ on a Cortecs $\mathrm{C} 18$ column $(150 \times 4.6 \mathrm{~mm}, 2.7 \mu \mathrm{m})$ (Waters), with a mobile phase flow rate of $1.0 \mathrm{~mL} / \mathrm{min}$. Composition of eluent $\mathrm{A}$ was $0.1 \%(\mathrm{v} / \mathrm{v})$ trifluoroacetic acid (TFA) in water $(\mathrm{pH}$ 1.9), eluent $B$ was a mixture of acetonitrile and water in $95: 5(\mathrm{v} / \mathrm{v})$ with $0.1 \%(\mathrm{v} / \mathrm{v})$ TFA. A linear gradient of $15-65 \% \mathrm{~B}$ was applied at a range of 0-17 min. The MSD operating parameters were as follows: ESI positive ionization, scan ion mode (100-600 m/z), drying gas temperature $350{ }^{\circ} \mathrm{C}$, nitrogen flow rate $12 \mathrm{Lmin}^{-1}$, nebuliser pressure 40 psi, capillary voltage $2500 \mathrm{~V}$, fragmentor voltage $60 \mathrm{~V}$.

\subsubsection{General procedure $A$}

Synthesis of 7, 8 and $\mathbf{9 , 1 0}$ products using continuous flow one-pot reductive cyclisation method, starting from 5, 6 and 11, 12: The appropriate starting materials were completely dissolved in glacial acetic acid in a flask under nitrogen $(0.05 \mathrm{M})$. The reaction parameters, including temperature $\left(150{ }^{\circ} \mathrm{C}\right)$, liquid flow rate $\left(0.5 \mathrm{mLmin}^{-1}\right)$, and hydrogenation gas pressure (20 bar), were selected on H-Cube $\mathrm{Pro}^{\circledR}$ (catalyst cartridge: $30 \mathrm{~mm} 5 \% \mathrm{Pt} / \mathrm{C}$, Sulfided), and the system was conditioned by pumping only pure solvent (glacial acetic acid) through the flow reactor for at least $30 \mathrm{~min}$. After the system stabilized, the substrate solution was introduced. The reaction was complete after a single passage through the apparatus and the product stream was continuously collected in a gas-liquid separator.

\subsubsection{General procedure B}

Synthesis of 9 using continuous flow one-pot reductive cyclization and a subsequent dehydration step: Compound 5 was completely dissolved in glacial acetic acid in a flask under nitrogen $(0.05 \mathrm{M})$. The parameters of onepot reductive cyclization were conditioned as described before in general procedure A. From the gas-liquid separator the crude reaction solution pumped with a HPLC pump to an Asia heater module, with 4 or $16 \mathrm{~mL}$ reactor volume, and a back pressure regulator was attached at the end (250 or $350 \mathrm{psi}$ ). The reaction was complete after a single passage through the apparatus and the product stream was continuously collected.

\subsubsection{General procedure $C$}

Optimization of acetylation using microwave reactor: A mixture of $o$-nitroaniline (15) and succinic anhydride (16), the catalyst (50 w\% Amberlyst XN-1010 ion exchange resin, or $\mathrm{AcOH})$, solved in the appropriate solvent $(2 \mathrm{~mL})$ and was heated at $100-200{ }^{\circ} \mathrm{C}$ under $\mathrm{N}_{2}$ in a closed vial in CEM Discover Microwave reactor equipped with a pressure controller applying $220 \mathrm{~W}$ for $30 \mathrm{~min}$. After evaporation of the solvent the crude product obtained.

\subsubsection{General procedure D}

Synthesis of 7 using continuous flow acylation and a subsequent one-pot reductive cyclization: $o$-Nitroaniline $(\mathbf{1 5}$, for $0.05 \mathrm{M}$ solution) and succinic anhydride (16) (1.2 or 3 or 6 eq.) were completely dissolved in the appropriate solvent (20\% acetic acid, $80 \%$ toluene) in a flasks under nitrogen. An Asia heater module, with 4 or $16 \mathrm{~mL}$ reactor volume was connected to the $\mathrm{H}-\mathrm{Cube}$ Pro ${ }^{\circledR}$ with a $30 \mathrm{~cm}$ PTFE tube $\left(1 / 16^{\prime \prime}\right)\left(\mathrm{T} 1: 200{ }^{\circ} \mathrm{C}\right)$ (Table 4 , entry 17-20). In the case of entry 21-26, we pumped acetic acid to the reaction mixture after the Asia heater across a static T-mixer. The parameters of one-pot reductive cyclization were conditioned as described above in general procedure $\mathrm{A}$. The reaction was complete after a single passage through the apparatus and the product stream was continuously collected.

\subsection{Synthesis of 4-((2-nitrophenyl)amino)-4- oxobutanoic acid (5) [19]}

To a vigorously stirred solution of $o$-nitroaniline $(1.0 \mathrm{~g}, 7.5$ mmole) in acetic acid (20 $\mathrm{mL}), \mathbf{1 6}(8.25 \mathrm{mmole})$ was added in one lot. The reaction mixture was refluxed under nitrogen atmosphere for $72 \mathrm{~h}$. The cooled reaction mixture was concentrated by evaporation and the product was obtained by column chromatography using: hexane-ethyl acetate eluent system with silica gel $60(0.040-0.063 \mathrm{~mm})$. Yield: $62 \%$. ${ }^{1} \mathrm{H}-\mathrm{NMR}$ (DMSO- d6) $\delta_{\mathrm{H}}: 2.49$ (2H, t, J: 7.0), 2.60 (2H, t, J: 7.0), 7.45 (1H, td, J: 8.5, 1.5), 7.64 (1H, d, J: 8.0), 7.71 (1H, td, J: 8.5, 1.5), 7.93 (1H, dd, J: 8.0, 1.5), $10.30(1 \mathrm{H}$, br s), $12.17\left(1 \mathrm{H}\right.$, br s). ${ }^{13 \mathrm{C}} \mathrm{NMR}$ (DMSO- d6) $\delta_{\mathrm{C}}: 173.5$, $170.4,142.2,133.9,131.3,125.1,125.0,124.9,30.8,28.7$

\subsection{Synthesis of $N$-substituted cyclic amides $(11,12)$}

Acylated $o$-nitroaniline derivatives (about $200 \mathrm{mg}$, $2.1 \mathrm{mmol}, 1$ eq.) were dissolved in $\mathrm{Ac}_{2} \mathrm{O}(5 \mathrm{~mL})$ separately and the mixtures were stirred for $5 \mathrm{~h}$ at $100^{\circ} \mathrm{C}$. The acetic anhydride was removed under vacuum, the resulting brown solid was washed with cold acetone and then dried under reduced pressure to give the pure product.

\subsubsection{1-(2-Nitrophenyl)pyrrolidine-2,5-dione (11) [20]} Yield: $58 \%$ \% ${ }^{1} \mathrm{H}-\mathrm{NMR}\left(\mathrm{CDCl}_{3}\right) \delta_{\mathrm{H}}: 2.96(4 \mathrm{H}, \mathrm{m}), 7.39(1 \mathrm{H}$, dd, $J: 7.5,1.0), 7.63$ (1H, td, $J: 8.0,1.5), 7.77$ (1H, td, $J: 8.0$, 
1.5), 8.20 (1H, dd, $J: 8,0,1.0) .{ }^{13} \mathrm{C} \mathrm{NMR}\left(\mathrm{CDCl}_{3}, 126 \mathrm{MHz}\right)$ $\delta_{\mathrm{C}}: 175.4,134.5,130.6,130.2,126.1,28.8$.

\subsubsection{1-(2-Nitrophenyl)piperidine-2,6-dione (12) [21]} Yield: $54 \%$. ${ }^{1} \mathrm{H}-\mathrm{NMR}\left(\mathrm{CDCl}_{3}\right) \delta_{\mathrm{H}}: 2.15(2 \mathrm{H}, \mathrm{m}), 2.83(4 \mathrm{H}$, m), 7.28 (1H, dd, J: 7.5, 1.0), 7.61 (1H, td, J: 7.5, 1.5), 7.72 $(1 \mathrm{H}, \mathrm{td}, J: 7.5,1.5), 8.21(1 \mathrm{H}, \mathrm{dd}, J: 8.0,1.5) .{ }^{13} \mathrm{C} \mathrm{NMR}$ $\left(\mathrm{CDCl}_{3}\right) \delta_{\mathrm{C}}: 172.3,134.5,131.9,129.9,126.0,32.9,17.0$.

4.4 Synthesis of 2-substituted benzimidazole derivatives using continuous flow $(7,8)$

\subsubsection{3-(1H-Benzo[d]imidazol-2-yl)propanoic acid (7)}

[12]

${ }^{1} \mathrm{H}$ NMR (DMSO-d6): $\delta_{\mathrm{H}} 12.2(1 \mathrm{H}, \mathrm{s}), 7.47$ (2H, dd, J: 6.0, 3.3), 7.13 (2H, dd, J: 6.0, 3.0), 3.04 (2H t, J: 7.5), $2.76(2 \mathrm{H}$ t, $J: 7.5) .{ }^{13} \mathrm{C}$ NMR (75 MHz, DMSO-d6): $\delta_{\mathrm{C}} 173.5,154.0$, $138.6,121.2,14.4,31.3,23.8$.

4.4.2 4-(1H-Benzo[d]imidazol-2-yl)butanoic acid (8) [22] ${ }^{1} \mathrm{H}$ NMR (DMSO-d6): $\delta_{\mathrm{H}} 7.48(2 \mathrm{H}, \mathrm{dd}, J: 6.0,3.3), 7.18(2 \mathrm{H}$ dd, J: 6.0, 3.0), 2.94 (2H t, J: 7.3), 2.31 (2H, m), 2.11(2H, m). ${ }^{13} \mathrm{C}$ NMR (75 MHz, DMSO-d6): $\delta_{\mathrm{C}} 180.9,156.5,139.3$, $123.3,115.3,36.7,29.3,25.6$.

\section{References}

[1] Wu, L.-T., Jiang, Z., Shen, J., Yi, H., Zhan, Y.-C., Sha, M.-Q., Wang, Z., Xue, S., Li, Z. "Design, synthesis and biological evaluation of novel benzimidazole-2-substituted phenyl or pyridine propyl ketene derivatives as antitumour agents", European Journal of Medicinal Chemistry, 114, pp. 328-336, 2016.

https://doi.org/10.1016/j.ejmech.2016.03.029

[2] Reddy, T. S., Kulhari, H., Reddy, V. G., Bansal, V., Kamal, A., Shukla, R. "Design, synthesis and biological evaluation of 1,3-diphenyl- $1 H$-pyrazole derivatives containing benzimidazole skeleton as potential anticancer and apoptosis inducing agents", European Journal of Medicinal Chemistry, 101, pp. 790-805, 2015. https://doi.org/10.1016/j.ejmech.2015.07.031

[3] Labanauskas, L. K., Brukshtus, A. B., Gaidelis, P. G., Udrenaite, É. B., Daukshas, V. K. "Synthesis and Antiinflammatory Activity of Some New Derivatives of 6-Benzoyl-1,4-Benzodioxane", Pharmaceutical Chemistry Journal, 33(5), pp. 259-260, 1999. https://doi.org/10.1007/BF02510046

[4] Mariappan, G., Hazarika, R., Alam, F., Karki, R., Patangia, U., Nath, S. "Synthesis and biological evaluation of 2-substituted benzimidazole derivatives", Arabian Journal of Chemistry, 8(5), pp. 715-719, 2015.

https://doi.org/10.1016/j.arabjc.2011.11.008

[5] Hubschwerlen, C., Pflieger, P., Specklin, J. L., Gubernator, K., Gmünder, H. Angehrn, P. Kompis, I. "Pyrimido[1,6-a]benzimidazoles: A New Class of DNA Gyrase Inhibitors", Journal of Medicinal Chemistry, 35(8), pp. 1385-1392, 1992.

https://doi.org/10.1021/jm00086a006
4.5 Synthesis of benzimidazole lactam derivatives using continuous flow $(9,10)$

4.5.1 2,3-Dihydro-1 $H$-benzo[d]pyrrolo[1,2-a]imidazol1-one (9) [12]

${ }^{1} \mathrm{H}$ NMR $\left(\mathrm{CDCl}_{3}\right) \delta_{\mathrm{H}} 7.87(1 \mathrm{H}, \mathrm{d}, J: 7.5), 7.67(1 \mathrm{H} \mathrm{dd}, J$ : 7.2, 1.2), 7.38-7.28 (2H, m), 3.29-3.16 (4H, m). ${ }^{13} \mathrm{C}$ NMR $\left(\mathrm{CDCl}_{3}\right) \delta_{\mathrm{C}} 169.9,162.1,149.3,128.48,125.4,124.3,120.0$, 113.0, 34.5, 21.2.

\subsubsection{3,4-Dihydrobenzo[4,5]imidazo[1,2-a]pyridin- 1(2H)-one (10) [23]}

${ }^{1} \mathrm{H} \mathrm{NMR}\left(\mathrm{CDCl}_{3}\right) \delta_{\mathrm{H}} 8.79-8.76(1 \mathrm{H}, \mathrm{m}), 8.26-8.23(1 \mathrm{H}, \mathrm{m})$, 7.95-7.88 (2H, m), 3.68 (2H, t, J: 6.4), 3.36 (2H, t, J: 6.6), $2.75-2.67(2 \mathrm{H}, \mathrm{m}) .{ }^{13} \mathrm{C} \mathrm{NMR}\left(\mathrm{CDCl}_{3}\right) \delta_{\mathrm{C}} 169.0,154.3$, $134.8,125.2,120.2,119.2,116.7,115.4,33.7,25.1,20.3$.

\section{Acknowledgment}

B.SZ. thanks Gedeon Richter Talentum and the Pro Progressio Foundations for financial support. This work was performed in the frame of FIEK_16-1-2016-0007 project, implemented with the support provided from the National Research, Development and Innovation Fund of Hungary, financed under the FIEK_16 funding scheme.

[6] Mavrova, A. T., Yancheva, D., Anastassova, N., Anichina, K., Zvezdanovic, J., Djordjevic, A., Markovic, D., Smelcerovic, A. "Synthesis, electronic properties, antioxidant and antibacterial activity of some new benzimidazoles", Bioorganic \& Medicinal Chemistry, 23(19), pp. 6317-6326, 2015. https://doi.org/10.1016/j.bmc.2015.08.029

[7] Meegalla, S. K., Stevens, G. J., McQueen, C. A., Chen, A. Y. Yu, C., Liu, L. F., Barrows, L. R., LaVoie, E. J. "Synthesis and Pharmacological Evaluation of Isoindolo[1,2-b]quinazolinone and Isoindolo[2,1-a]benzimidazole Derivatives Related to the Antitumor Agent Batracylin", Journal of Medicinal Chemistry, 37(20), pp. 3434-3439, 1994.

https://doi.org/10.1021/jm00046a028

[8] Mamada, M., Pérez-Bolívar, C., Anzenbacher, P. "Green Synthesis of Polycyclic Benzimidazole Derivatives and Organic Semiconductors", Organic Letters, 13(18), pp. 4882-4885, 2011. https://doi.org/10.1021/ol201973w

[9] Al-Khathlan, H., Zimmer, H. "Dibromotriphenylphosphorane promoted synthesis of condensed heterocyclic systems from aromatic diamines", Journal of Heterocyclic Chemistry, 25(3), pp. 1047-1049, 1988 https://doi.org/10.1002/jhet.5570250367

[10] Alkhathlan, H. Z., Al-lohedan, H. A. "Application of Phosphorus, Arsenic and Antimony Reagents in the Synthesis of Heterocyclic Compounds", Phosphorus, Sulfur, and Silicon and the Related Elements, 61(3-4), pp. 367-372, 1991. https://doi.org/10.1080/10426509108036819 
[11] Crenshaw, M. D., Zimmer, H. "Pyrrolo- and Pyrido[1,2-a]indoles via an Intramolecular Wittig Reaction", Journal of Heterocyclic Chemistry, 21(2), pp. 623-624, 1984. https://doi.org/10.1002/jhet.5570210275

[12] Bastug, G., Eviolitte, C., Markó, I. E. "Functionalized Orthoesters as Powerful Building Blocks for the Efficient Preparation of Heteroaromatic Bicycles", Organic Letters, 14(13), pp. 3502-3505, 2012. https://doi.org/10.1021/o1301472a

[13] Cul, A., Daïch, A., Decroix, B., Sanz, G., Van Hijfte, L. "Kinetic versus thermodynamic access to imidazoisoindolones, benzimidazoisoindolones, and [1,4]diazepinoisoindolones: intramolecular nitrogen and $\pi$-aromatic trapping of $N$-acyliminium cation", Tetrahedron, 60(48), pp. 11029-11039, 2004. https://doi.org/10.1016/j.tet.2004.07.107

[14] Menke, E. H., Lami, V., Vaynzof, Y., Mastalerz, M. " $\pi$-Extended rigid triptycene-trisaroylenimidazoles as electron acceptors", Chemical Communications, 52(5), pp. 1048-1051, 2016. https://doi.org/10.1039/C5CC07238G

[15] Szabó, B., Faigl, F., Éles, J., Greiner, I. "A Novel One-pot Benzimidazole Ring Formation via a Continuous Flow Selective Reductive Cyclization Method", Current Organic Chemistry, 22(19), pp. 1940-1944, 2018. https://doi.org/10.2174/1385272822666180829100850

[16] Razzaq, T., Kappe, C. O. "Continuous Flow Organic Synthesis under High-Temperature/Pressure Conditions", Chemistry - An Asian Journal, 5(6), pp. 1274-1289, 2010. https://doi.org/10.1002/asia.201000010

[17] Wilson, N. S., Osuma, A. T., Camp, J. A. V., Xu, X. "A scalable approach to diaminopyrazoles using flow chemistry", Tetrahedron Letters, 53(34), pp. 4498-4501, 2012. https://doi.org/10.1016/j.tetlet.2012.05.152
[18] Glasnov, T. N., Kappe, C. O. "The Microwave-to-Flow Paradigm: Translating High-Temperature Batch Microwave Chemistry to Scalable Continuous-Flow Processes", Chemistry - A European Journal, 17(43), pp. 11956-11968, 2011. https://doi.org/10.1002/chem.201102065

[19] Patil, S. V., Mahale, K. A., Gosavi, K. S., Deshmukh, G. B., Patil, N. S. "Solvent-mediated One-Pot Synthesis of Cyclic $N$-Substituted Imides", Organic Preparations and Procedures International, 45(4), pp. 314-320, 2013. https://doi.org/10.1080/00304948.2013.798569

[20] Bunce, R. A., Smith, C. L., Knight, C. L. "N-(Nitrophenyl) Benzamide and Benzenesulfonamide Derivatives by Nucleophilic Aromatic Substitution", Organic Preparations and Procedures International, 36(5), pp. 482-487, 2004. https://doi.org/10.1080/00304940409356635

[21] Rajput, A. P., Girase P. D. "Synthesis of some biologically active 2,6-dichloro-1-(N-substituted phenyl)-1,4-dihydropyridine-3,5-dicarbaldehydes using Vilsmeier-Haack reaction and their applications", Indian Journal of Heterocyclic Chemistry, 21(3), pp. 201-208, 2012.

[22] Nicole V. C., Marcel D. "Synthése d'amino-2 Benzimidazoles" (Synthesis of amino-2 Benzimidazoles), Comptes Rendus Hebdomadaires des Séances de l'Académie des Sciences, 256(6), pp. 699-700, 1963. (in French)

[23] Elagawany, M., Ibrahim, M. A., Panda, S. S. " One-pot synthesis of bi- and tricyclic heterocyclic compounds using benzotriazole chemistry", Tetrahedron Letters, 57(44), pp. 4910-4913, 2016. https://doi.org/10.1016/j.tetlet.2016.09.070 